\title{
Sea-Effect Precipitation over the Shandong Peninsula, Northern China
}

\author{
BAOLEERQIMUGE BAO \\ Department of Atmospheric Science, School of Environmental Studies, China University of Geosciences, \\ Wuhan, and Forestry College, Inner Mongolia Agricultural University, Hohhot, and Chinese Academy of \\ Meteorological Sciences, Beijing, China
}

GUOYU REN

Department of Atmospheric Science, School of Environmental Studies, China University of Geosciences, Wuhan, and Laboratory for Climate Studies, National Climate Center, China Meteorological Administration, Beijing, China

(Manuscript received 18 July 2017, in final form 4 March 2018)

\begin{abstract}
Sea-effect precipitation (SEP) over the Shandong Peninsula is a unique climatological phenomenon in mainland China, and it exerts a considerable impact on the southern shore of the Bohai Sea. From observed data from 123 stations for the period 1962-2012, the characteristics of cold-season (November-February) SEP in this area were analyzed. Results showed that SEP occurred throughout the late autumn and winter. In all, 1173 SEP days were identified during the 51 years, of which snow days accounted for $73.7 \%$ and rain and snow-rain days accounted for $16.1 \%$ and $10.1 \%$, respectively. December had the largest number of SEP snow days, followed by January and November. November was the most productive month in terms of SEP rain and snow-rain days. Intense SEP snowfall mainly affected the inland hill area of the peninsula, whereas light SEP snowfall reached farther inland. SEP rainfall shared a similar pattern with snowfall. The SEP frequency showed a significant interannual variability and a nonsignificant upward trend over the period analyzed. SEP was most likely to occur when the temperature difference between sea surface and $850 \mathrm{hPa}$ over the Bohai Sea was above $10^{\circ} \mathrm{C}$, indicating a dominant influence of low-level cold-air advection over the sea on the generation and development of the weather phenomenon. A significant negative correlation was also found between the area of sea ice in the Bohai Sea and intense SEP snowfall, indicating that sea ice extent had an important effect on SEP variability over the peninsula. In the case of extremely intense SEP events, a deeper East Asian trough at the 500-hPa level developed over the southwest of the study area and temperature and geopotential height contours were orthogonal to each other, indicating strong geostrophic cold-air advection over the Bohai Sea and the Shandong Peninsula. The extremely intense SEP events were also characterized by anomalous low temperature and high relative humidity in the lower troposphere, which contributed to greater gravitational instability in the study area.
\end{abstract}

\section{Introduction}

Sea-effect precipitation (SEP) and lake-effect precipitation (LEP) are local or mesoscale precipitation phenomena that appear over and downwind of the sea or a lake (Laird et al. 2009a,b) when cold air flows over the relatively warmer water. They occur mostly in midhigh-latitude regions in late autumn and winter and are characterized by cloud streets, limited spatial distribution, short duration, and mostly snow (Steenburgh et al. 2000; Yu et al. 2009; Laird et al. 2009a,b). There are many studies on LEP (Braham and Dungey 1984; Burnett

\footnotetext{
Corresponding author: G. Ren, guoyoo@cma.gov.cn
}

et al. 2003). SEP occurs independently, although it can also enhance synoptic-scale precipitation (Tardy 2000). There exist many areas of the world where SEP and LEP occur frequently, for example, northwestern Japan (Ikeda et al. 2009), easterly wind-induced snowfall in the Yeong Dong region of the Korean Peninsula (Nam et al. 2014), the Black Sea (Kindap 2010), the Great Lakes in North America (Braham and Dungey 1984; Burnett et al. 2003), and the northeastern slope of the Caucasus Mountains to the west of the Caspian Sea (Farley Nicholls and Toumi 2014). Some smaller inland lakes can also trigger LEP, such as the Great Salt Lake (Steenburgh et al. 2000), Lake Champlain (Payer et al. 2007), and the Finger Lakes (Laird et al. 2010) in the United States. 
There is much research on LEP that focuses on different sizes of water bodies (Laird et al. 2009a,b; Steenburgh et al. 2000; Payer et al. 2007). Several aspects of LEP have been analyzed, such as initial and ending time, duration time, surface temperature, lakeair temperature difference, sea-land breeze, and other atmospheric conditions. LEP mostly is initiated overnight and in the morning and dissipates in the afternoon (Laird et al. 2009a). The duration of individual LEP events varies with the size of the water bodies. The average duration is $9.4 \mathrm{~h}$ for the New York State Finger Lakes (six easternmost Finger Lakes, ranging in surface area from 7.6 to $175 \mathrm{~km}^{2}$; Laird et al. 2009b), $12.1 \mathrm{~h}$ for Lake Champlain $\left(1127 \mathrm{~km}^{2}\right.$; Laird et al. 2009a), $19.5 \mathrm{~h}$ for Lake Ontario (the smallest of the Great Lakes at $18960 \mathrm{~km}^{2}$ ) and the Tug Hill region (Veals and Steenburgh 2015), and even up to multiple days for larger water bodies of the Great lakes (Laird et al. 2009a). The $850-\mathrm{hPa}$ temperature is an important air condition for the development of LEP and has been used as an important indicator for forecasting LEP (Laird et al. 2009a). Near-surface temperature can also be a good reference index for different LEP types, with mostly LEP as rain when the temperature is above freezing and as snow when the temperature is below freezing (Miner and Fritsch 1997).

Many studies have documented the various factors that influence LEP, such as the lake breeze (Passarelli and Braham 1981; Laird et al. 2009a; Alcott et al. 2012), upper-air troughs, surface cold fronts, wind shear, lake-air temperature differences, lake-land temperature differences (Steenburgh et al. 2000), and lake ice extent (Cordeira and Laird 2008). Burnett et al. (2003) showed that the extent of lake/sea ice has become smaller with global warming, enhancing the frequency and intensity of LEP in the Great Lakes. A comparison was given for LEP among different water areas in the studies of Lake Champlain and the Finger Lakes of New York (Laird et al. 2009a,b, 2010).

Climatological analysis on LEP has also been conducted for different lakes (Steenburgh et al. 2000; Laird et al. 2009a,b, 2010; Alcott et al. 2012; Veals and Steenburgh 2015; Laird et al. 2016). The time periods selected in these papers mostly started in the mid-1990s when WSR-88D data were available. By use of radar data, LEP days can be accurately identified and classified into different types, including pure LEP, transition type, synoptic-scale precipitation enhanced type, and enhanced precipitation of upstream water body (Laird et al. 2009a, 2010).

Numerous Chinese researchers have investigated SEP, which is also called "cold flow precipitation" by the authors, in the Shandong Peninsula (Zhou et al.
2008; Yang et al. 2009; Jiang et al. 2010; Zhu et al. 2010). These works encompassed such topics as mesoscale characteristics (Yang et al. 2007a; Zhang et al. 2008), diagnostic analyses (Shan et al. 2006; Li et al. 2011), possible mechanisms (Yu et al. 2009), orographic influence (X. Zhou et al. 2011), and high-level air condition (Chu and $\mathrm{Li} 2012$ ). The first issue in the research was the segregation of SEP days. The previous studies utilized different methods to differentiate the SEP types for different purposes, but they were mostly based on the data of radar-echo maps (Yang et al. 2007a), low-level winds, and precipitation fields (Yang et al. 2007b).

Overall, the studies of SEP in the Shandong Peninsula were mostly based on case analyses of synoptic features, with little emphasis given to climatological analysis. Climatological analyses of SEP have been done only in recent years (S. Zhou et al. 2011; Yang et al. 2007b). S. Zhou et al. (2011) only analyzed SEP snow and found that the heavy SEP snowfall was mostly distributed in the eastern part of the Shandong Peninsula and that there was an annual mean of 0.9 days of heavy snowfall on the whole peninsula. Yang et al. (2007b) found that the SEP snow events generally occurred in the northeastern part of the Shandong Peninsula and that they exhibited a rapid decline from there toward the southwest of the peninsula. The two studies did not analyze snow-rain and rain, nor did they examine the long-term change in the SEP snow events. In addition, there had been less focus on the sea-effect rainfall, probably because of the relatively reduced socioeconomic effects when compared with the seaeffect snowfall.

In this paper, we differentiated SEP days from other categories of precipitation according to the daily wind field and spatial distribution of daily precipitation. Seaeffect rain, snow, and snow-rain days were identified using weather records. We then analyzed the climatology characteristics and long-term variation of frequency and intensity of the different types of SEP. The findings of this paper could contribute to in-depth understanding of the mechanisms of the cold-season SEP in the Shandong Peninsula.

\section{Study area, data, and methods}

Figure 1 shows the study area and the spatial coverage of the meteorological observation stations. In this investigation, we defined the Shandong Peninsula as the area east of $119^{\circ} \mathrm{E}$ and north of $35^{\circ} \mathrm{N}$. The peninsula is located to the south of the Bohai Sea (about $77000 \mathrm{~km}^{2}$ ). Most of the peninsula area is hilly land, with the eastwest-oriented Laishan Hill area (about 200-500 m high) 

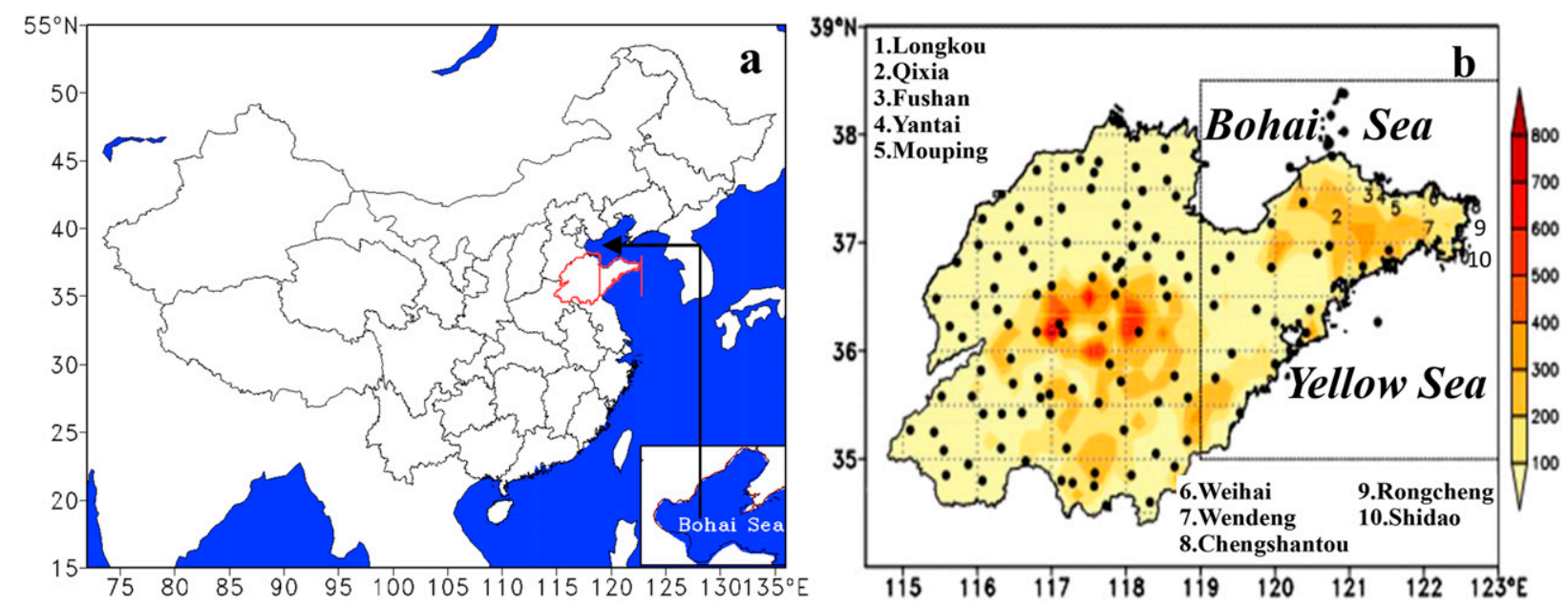

FIG. 1. (a) Study area, with the inset map showing the Bohai Sea at large, giving the locations of Shandong Province and the Shandong Peninsula. The boundary of the province is in red, with the eastern and western ends of the peninsula labeled by two vertical red lines. (b) An enlargement of the province, showing the distribution of meteorological stations. The color bar and contours are in meters, indicating height above sea level.

located at approximately $37.2^{\circ} \mathrm{N}$. The northeastern coast of the peninsula is affected frequently by SEP, which sometimes causes severe snowstorms or rainstorms; for example, the heavy sea-effect snowfall of 3-21 December 2005 over the Shandong Peninsula caused severe impacts to transport and communications. Four SEP intense snow events were identified during this period (Zhou et al. 2008).

Figure 2 shows the accumulated snow cover on 19 December 2005 (Fig. 2a), and typical SEP cloud images for three days during the SEP process (Figs. 2b-d). The cumulative precipitation (water equivalent after melting) recorded at the Yantai and Weihai stations is 80.3 and $88.5 \mathrm{~mm}$, respectively, being the most long-lasting and heaviest snowfall process for these two stations since precipitation began being recorded (Yantai since 1961; Weihai since 1959). This snowstorm caused significant damage to the Shandong Peninsula, resulting in the death of 13300 poultry and the collapse of 2362 greenhouses and 73 houses in Weihai city. Also, flights were canceled, transportation was stalled, and schools were closed in the worst-hit area of the city. It brought about a 5 million yuan economic loss for Yantai and Weihai (Huang et al. 2008; Li et al. 2009). This long-lasting SEP snowfall occurrence was confirmed as one of the 10 most influential weather and climate events in mainland China in 2005. Because of the severe damage brought by the heavy SEP snowstorm, there have been case studies of this snowfall event (e.g., Jiang et al. 2010; Li et al. 2009).

The three infrared cloud photographs in Figs. 2b, 2c, and $2 \mathrm{~d}$ show the morphology of the clouds in the typical SEP snow process. They are for 1400 Japan standard time (JST) 4 December 2005, 1400 JST 12 December 2005, and 1400 JST 17 December 2005, respectively. The satellite cloud images show that, for Shandong Peninsula SEP snow, low clouds are most frequently formed, with disorganized cells in the early stage but becoming densely arranged later over the northern coastal area (Zheng et al. 2003). Southwest-northeastoriented cloud lines are observed that are almost vertical to the northwestern wind (Zhou et al. 2008). A cyclonic pattern is also observed for the SEP cumulus cloud (Jiang et al. 2010). Satellite images of another SEP snow day (5 December 2008) shows patterns of clouds that are similar to those of December 2005.

The National Meteorological Information Center of the China Meteorological Administration provided the data for the daily records of precipitation, temperature, and weather phenomena for November-February cold seasons for 1962-2012 (where the year indicates the end point of the cold season) for 123 stations in Shandong Province (Fig. 1b). Daily data for wind, temperature, relative humidity, and geopotential height at different pressure levels (at $2.5^{\circ} \times 2.5^{\circ}$ horizontal resolution) were obtained from the U.S. National Oceanic and Atmospheric Administration/National Centers for Environmental Prediction (NOAA/NCEP). Because sea surface temperature (SST) had little variation over the course of a given week, we used weekly instead of daily mean data. The weekly SST data during 1981-2012 were obtained from the NOAA National Climatic Data Center Optimum Interpolation Sea Surface Temperature (OISST). The $24 \mathrm{~km} \times 24 \mathrm{~km}$ daily sea ice data from the Interactive Multisensor Snow and Ice Mapping System (IMS) of the 


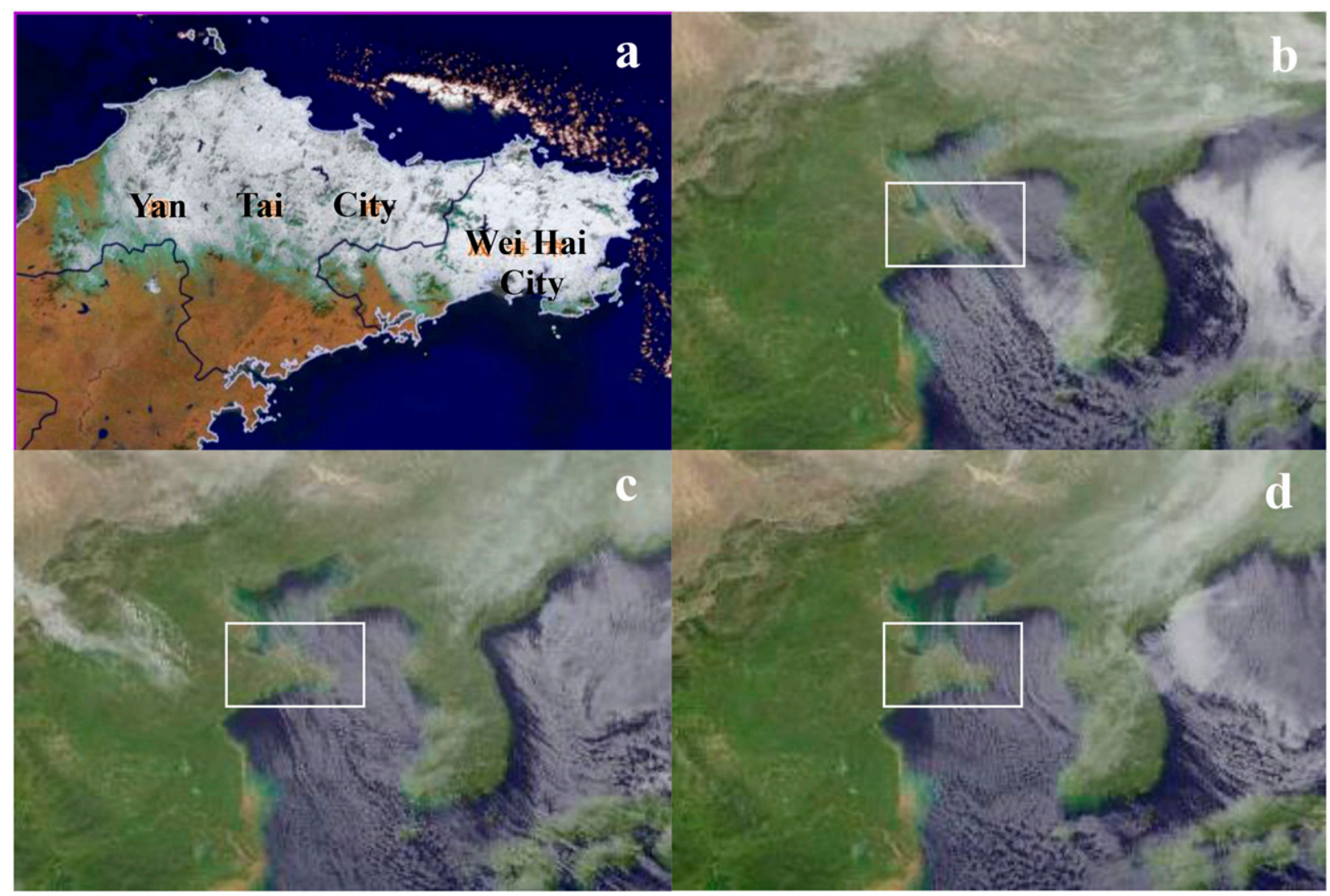

FIG. 2. (a) Snow cover on 19 Dec 2005 in the Shandong Peninsula as monitored by Earth Observing System satellite, and satellite infrared cloud images (from http://weather.is.kochi-u.ac.jp/sat/gms.fareast) at 1400 JST (b) 4, (c) 12, and (d) 17 Dec 2005 . The SEP process lasted from 3 to 21 Dec 2005. The study region is indicated by the rectangle in (b), (c), and (d).

NOAA National Ice Center for the period 1997-2012 were utilized in the analysis.

Previous studies mostly used radar reflectivity maps or satellite cloud charts to separate and classify SEP and LEP from synoptic-scale precipitation (e.g., Laird et al. 2009a,b; Alcott et al. 2012). In addition, the sea/lake-air temperature difference was used as an important criterion for indicating the occurrence of SEP and LEP events, and the difference between water surface temperature and air temperature was generally applied in some studies (Sun et al. 2007; Cui et al. 2008). The daily distribution of precipitation has also been used to identify SEP and LEP (Yang et al. 2007b).

This paper was designed to examine climatological characteristics and long-term variation of SEP events using data of the last half century; the radar and satellite records were not available for the early decades. Therefore, we developed a new procedure to identify SEP days. The procedure refers to the previous studies (Yang et al. 2007b; Zhou et al. 2008; Zhu et al. 2010), taking such criteria as spatial pattern of precipitation, location of maximum precipitation, and surface wind direction or $850-\mathrm{hPa}$ wind direction into consideration. These represent the most important features of a typical SEP event. To qualify as a SEP day, the daily precipitation and low-tropospheric wind had to meet the following criteria:

1) Only the Shandong Peninsula area recorded precipitation, and no precipitation was observed inland in Shandong Province. This was determined from the daily precipitation distribution maps of each day of the cold season for the period 1962-2012 in Shandong Province (precipitation amount in this paper is liquid equivalent precipitation, and the unit is millimeters).

2) The maximum precipitation center was located along the shores of the Bohai Sea, typically in the northeastern part of the peninsula.

3) The $850-\mathrm{hPa}$ wind direction over the Shandong Peninsula was any of northerly, northeasterly, and northwesterly. Cold airflow supply from the Bohai Sea was a precondition for SEP formation on the peninsula.

We verify the applicability of the above criteria in identifying a SEP event in the study area by examining a 
TABLE 1. Precipitation types and grades (defined in millimeters) of SEP on the Shandong Peninsula.

\begin{tabular}{clc}
\hline \hline $\begin{array}{c}\text { Precipitation } \\
\text { types }\end{array}$ & \multicolumn{1}{c}{$\begin{array}{c}\text { Intensity } \\
\text { grade }\end{array}$} & $\begin{array}{c}\text { 24-h amount }(\mathrm{mm}) \\
\text { (liquid water equivalent amount) }\end{array}$ \\
\hline Snow & Light snow & $<2.5$ \\
& Moderate snow & $2.5-5.0$ \\
& Heavy snow & $5.0-10.0$ \\
& Intense snow & $>10.0$ \\
Rain & Light rain & $<10.0$ \\
& Moderate rain & $10.0-25.0$ \\
& Heavy rain & $25.0-50.0$ \\
\hline
\end{tabular}

typical sea-effect snowfall event on 3-8 December 2005. The example shows that all of the criteria were met in the event, with the precipitation in the 6 days almost all distributed on the peninsula, the maximum precipitation occurring along the shores of the Bohai Sea (Fig. 2), and the surface and $850-\mathrm{hPa}$ wind directions in the study area being northerly and northwesterly. A total of 6133 days, with 1530 days for November, 1581 days for December, 1581 days for January, and 1441 days for February, were identified as winter SEP precipitation days during 1962-2012. The SEP days were then divided into three types: snow, rain, and snow-rain (rain and snow occurred on the same day).

From the SEP days, we determined the station that had the largest precipitation amount on each of the SEP days. We then designated the weather phenomenon of the site with the maximum precipitation as the SEP type for that day. In cases in which weatherphenomenon records were unavailable, records from nearby sites and other meteorological parameters were used for the designation.

Snow and rain were categorized in terms of intensity. The SEP that generated the maximum amount of precipitation (liquid water equivalent amount) at any of the observational sites was used to determine the precipitation category. A set of specific criteria that are based on the set used by the China Meteorological Association is presented in Table 1. As shown in the table, light snow, moderate snow, heavy snow, and intense snow have an accumulated maximum precipitation amount of $<2.5,2.5-5.0,5.0-10.0$, and $>10.0 \mathrm{~mm}$ within $24 \mathrm{~h}$, respectively, and light rain, moderate rain, and heavy rain have an accumulated maximum precipitation amount of $<10.0,10.0-25.0$, and $25.0-50 \mathrm{~mm}$ within $24 \mathrm{~h}$, respectively. No intense rain was found in the study area in winter. Winter months (or the cold season) in this investigation include November and December as well as January and February of the following year.

To understand the favorable atmospheric conditions for SEP, we conducted a composite analysis on different types of SEP on the basis of NCEP reanalysis datasets of geopotential height, relative humidity, temperature, and upper wind field (Kalnay et al. 1996). Using the anomaly-standard deviation method, we selected anomalously heavy SEP days of snow, rain, and snowrain by using the following formula:

$$
k_{i}=\left(x_{i}-\bar{x}\right) / \sigma_{x} \geq a,
$$

where $\sigma_{x}$ is standard deviation, $x_{i}$ is annual precipitation amount, $\bar{x}$ is the long-term annual mean precipitation amount, and $a$ is abnormal index as defined by the World Meteorological Organization, with the precipitation regarded as abnormal in cases of $a>2$ (Tan 1992).

For SEP snow days, we defined $a=5$, and thus four SEP snow days were determined to be anomalous SEP events (1 December 1990 with maximum snowfall of $247 \mathrm{~mm}$, 4 December 2005 with maximum snowfall of $270 \mathrm{~mm}$, 7 December 2005 with maximum snowfall of $244 \mathrm{~mm}$, and 5 December 2008 with maximum snowfall of $265 \mathrm{~mm}$ ). For SEP rain days, we defined $a=3$, and four SEP rain days were determined to be anomalous or extremely intense SEP rain events (21 November 1963 with maximum rainfall of $407 \mathrm{~mm}, 7$ November 1975 with maximum rainfall of $197 \mathrm{~mm}, 24$ November 1999 with maximum rainfall of $245 \mathrm{~mm}$, and 1 November 2004 with maximum rainfall of $269 \mathrm{~mm}$ ). For SEP snow-rain days, we defined $a=2.3$, and also four days were determined to be anomalous SEP events (4 November 1962 with maximum precipitation amount of $169 \mathrm{~mm}, 16$ November 1983 with maximum precipitation amount of $196 \mathrm{~mm}, 11$ November 1985 with maximum precipitation amount of $174 \mathrm{~mm}$, and 15 November 2009 with maximum precipitation amount of $223 \mathrm{~mm}$ ).

We used the more-extreme events in analyzing the influence of atmospheric circulation on their formation and development because they usually caused more severe damage to the local society and economy. This is also related to the normally low precipitation in the study area as compared with the other regions of the

TABLE 2. Total numbers and percentages of days with different types of SEP over the Shandong Peninsula.

\begin{tabular}{|c|c|c|c|c|c|c|c|c|}
\hline \multirow[b]{2}{*}{ Grade } & \multicolumn{4}{|c|}{ Snow } & \multicolumn{3}{|c|}{ Rain } & \multirow[b]{2}{*}{ Snow-rain } \\
\hline & Intense & Heavy & Moderate & Light & Heavy & Moderate & Light & \\
\hline No. of days & 50 & 94 & 126 & 595 & 2 & 11 & 176 & 119 \\
\hline Percentage (\%) & 4.3 & 8.0 & 10.7 & 50.7 & 0.2 & 0.9 & 15.0 & 10.1 \\
\hline
\end{tabular}



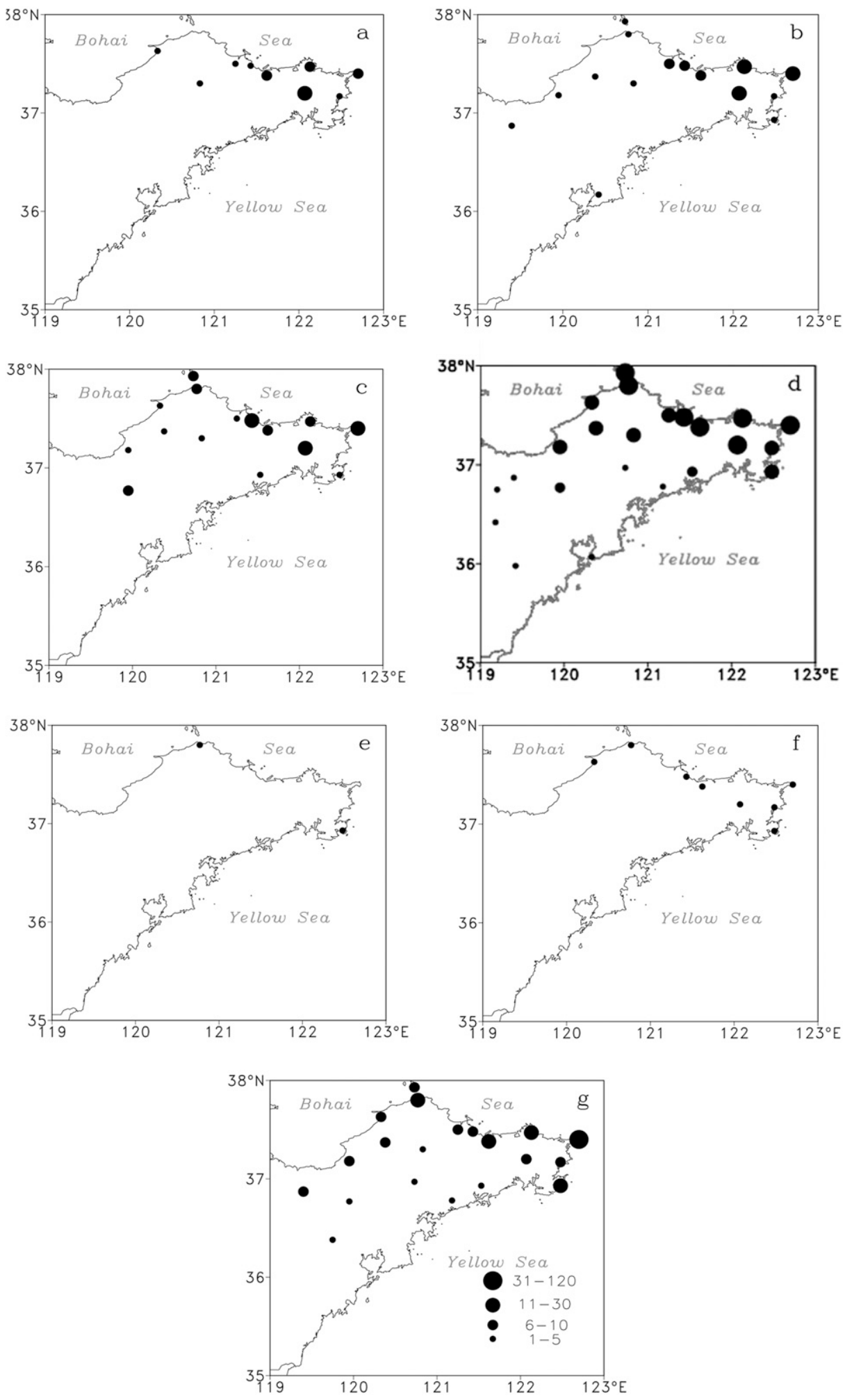

FIG. 3. Spatial distribution of number of days [see key in $(\mathrm{g})$ ] for different types of SEP over the Shandong Peninsula: (a) intense snow, (b) heavy snow, (c) moderate snow, (d) light snow, (e) heavy rain, (f) moderate rain, and (g) light rain. 
world and the more-extreme events would be characterized by a more typical circulation field.

\section{Results}

\section{a. Spatial and temporal characteristics}

Table 2 shows the number of days with different types of SEP. In all, 1173 (23 days $\mathrm{yr}^{-1}$ on average) SEP days were identified during 1962-2012, among which 865 $\left(73.7 \%\right.$, or $17{\text { days } y^{-1}}^{-1})$ were snow days, $189(16.1 \%$, or $3.7{\left.\text { days } \mathrm{yr}^{-1}\right)}^{-1}$ were rain days, and $119(10.1 \%$, or 2.3 days $^{-1}{ }^{-1}$ ) were snow-rain days. SEP was therefore predominantly snowfall events. Because snowfall was more likely to cause severe damage than rainfall, greater attention had been previously focused on snowfall, largely neglecting rain and snow-rain days. Rain days and snow-rain days accounted for $26.2 \%$ of the total SEP days, however, and they could sometimes also bring heavy precipitation; therefore, the occurrence and influence of SEP rain days and snow-rain days should not be overlooked.

Through the analysis of the amount of precipitation on snow days, the total numbers of different snowfall in-

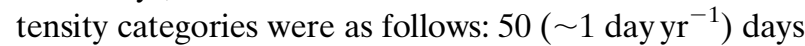

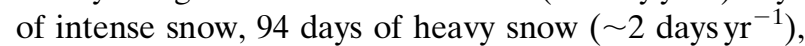
126 days of moderate snow $\left(\sim 2.5\right.$ days yr $\left.^{-1}\right)$, and 595 days

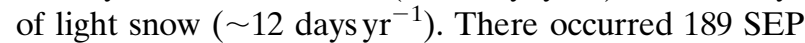
rain days, with 2 days of heavy rain, 11 days of moderate rain and 176 days of light rain (about $93 \%$ of the total rain days). Figure 3 presents the spatial distributions of different types and grades of SEP. The areas of maximum precipitation for all three types were located to the east of Yantai City, along the northern coastal zone.

An examination of the spatial distribution of SEP (Figs. 2 and 3) revealed that Wendeng was the area most frequently affected by intense sea-effect snow, followed by Weihai, Chengshantou, and Mouping. Heavy snowfall was concentrated mainly in the easternmost Chengshantou and Wendeng stations, which might be partly related to the warmer SST of the eastern Bohai Sea and westernmost part of the Yellow Sea. Moderate snowfall shared the same spatial pattern as heavy snow. Overall, the northern coastal zone represented by the Yantai, Weihai, and Wendeng stations was the area most frequently affected by intense SEP events, with the moderate and stronger SEP days accounting for more than one-half of all SEP days. The extent of SEP was broader during light-SEP events, when SEP precipitation reached inland areas of the peninsula. There were 189 rain days, with the maximum rainfall of $40.7 \mathrm{~mm}$ recorded on 21 November 1963 and centered in the vicinity of the Shidao station in the eastern coastal zone of the peninsula. Heavy and moderate sea-effect
TABLE 3. Monthly and annual mean number of days with different types and grades of SEP.

\begin{tabular}{lccccc}
\hline \hline Category/grade & Nov & Dec & Jan & Feb & Cold season \\
\hline Snow & & & & & \\
Intense snow & 0.4 & 0.5 & 0.1 & 0 & 1.0 \\
Heavy snow & 0.2 & 1.1 & 0.5 & 0.1 & 1.8 \\
Moderate snow & 0.4 & 1.1 & 0.8 & 0.2 & 2.5 \\
Light snow & 0.8 & 3.5 & 4.8 & 2.6 & 11.7 \\
Sum & 1.7 & 6.3 & 6.2 & 2.8 & 17.0 \\
Rain & 2.6 & 0.6 & 0.3 & 0.3 & 3.7 \\
Snow-rain & 1.2 & 0.7 & 0.3 & 0.2 & 2.3 \\
\hline
\end{tabular}

rainfall more frequently occurred along the coastal zones as compared with the intense sea-effect snowfall, with inland regions receiving only light SEP rainfall. The prevalence of more intense snowfall farther inland when compared with rainfall might be related to the effect of higher sea surface temperature, relatively low land surface temperature, and the orographic enhancement of inland hills. In addition, 119 snow-rain days were identified, with the maximum amount of daily precipitation recorded at $22.9 \mathrm{~mm}$.

Table 3 and Fig. 4 present the seasonality of different types of SEP. The SEP was typically in the form of mixed snow and rain during November, and thereafter it was almost exclusively snow. The greatest number of snow days occurred in December, followed by in January, and the fewest snow days occurred in November. December was the month most prone to intense snow days, with November ranked second, and no intense snow days appeared in February. A similar seasonal distribution was seen for heavy and moderate snowfall. In contrast, light snowfall occurred mainly in January, followed by in December, and occurred least frequently in November.

Figure 4a displays a histogram showing the temporal variation of the total number of SEP days in 10-day bins. The total number of SEP days in the study region reached 24, 30.7, and 36.7 days for the first, second, and third 10-day bins of the month, respectively. In the first two 10-day bins of the winter, most SEP events appeared as rain; the number decreased throughout the winter, whereas SEP snow showed a significant increase afterward. SEP snow showed two maximum values during the cold season, with late December (third 10-day bin; 135 days) and late January (third 10-day bin; 115 days) seeing the maximum values. SEP snow dominated SEP from late November to the end of the cold season. Late November had the maximum SEP snow-rain value (24 days). It had a similar contribution to the total SEP as SEP rain. Sea-effect snow-rain days could occur in any month but peaked in late November and early December and decreased in frequency to the end of 

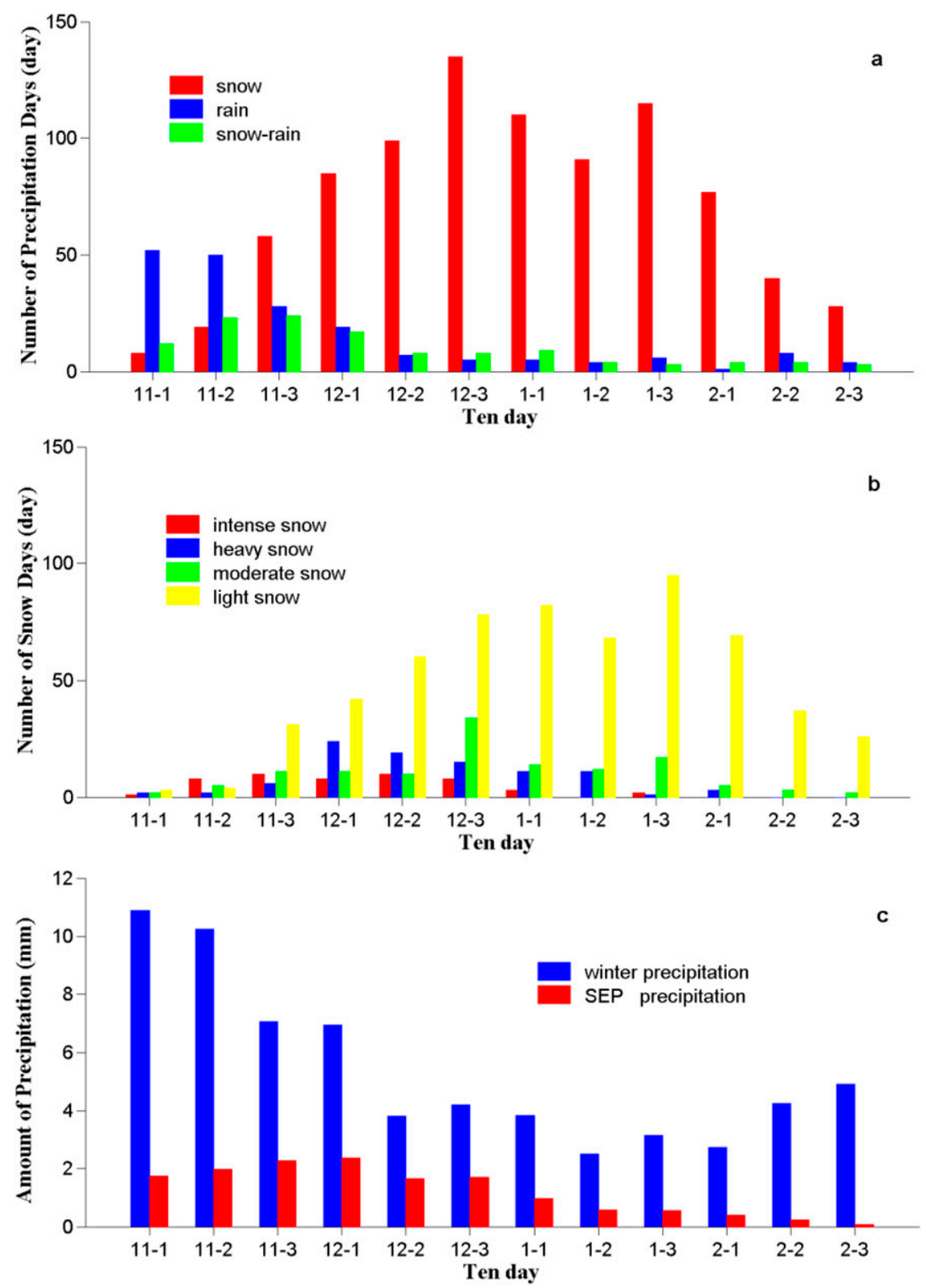

FIG. 4. Seasonal distribution of precipitation days and amount of different types in 10-day bins (e.g., 11-1 indicates the first 10-day bin for November) during 1962-2012: (a) accumulated number of days for different types of precipitation in 10-day bin during 1962-2012, (b) accumulated number of days for different ranks of snow in 10-day bin during 1962-2012, and (c) mean amount of precipitation for cold season and SEP in 10-day bins during 1962-2012.

February. This phenomenon was distributed mainly throughout November and December, with late November and early December having the peak. The intensity and frequency of snow-rain days apparently decreased from the beginning of November to the end of February. Late November was a transition period for both rain and snow. A sharp decrease of rain and an increase of snow were detected during this time. In all, SEP was mostly snowfall, and late November and early
December could be regarded as a transition period for different types of SEP.

Figure $4 \mathrm{~b}$ shows snow frequency for different grades of SEP snow. Mid-November showed an increase in snowfall of different intensities. By the end of November, there was a sharp increase in the frequency of light snow. Although there was less snowfall in November overall, it was of high intensity, and all grades of snow could occur. Snowfall of different intensities 


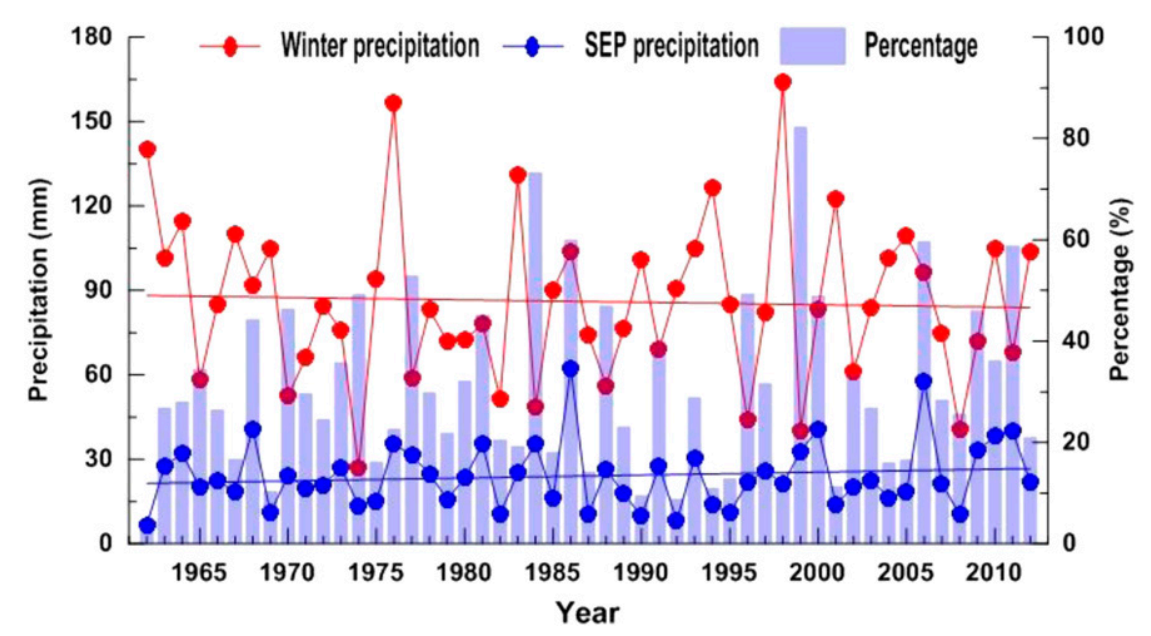

FIG. 5. Regional averaged annual cold-season total precipitation and SEP over the Shandong Peninsula during 1962-2012.

increased in December; snowfall of greater than $20 \mathrm{~mm}$ (intense snow) was concentrated mainly in early December. Mid-December was the peak time for the development of SEP snow. Intense snowfall was also seen in early January, although snowfall intensity decreased during the middle 10-day bins of the month. Snowfall intensity continued to weaken during the last 10-day bins, although light snowfall was still commonly seen during this time. No intense snow occurred in February, and both precipitation intensity and frequency markedly decreased. November was the peak time for rain days, accounting for $68.8 \%$ of the total SEP rains, followed by December with $16.4 \%$, and February showed the fewest rain days. Figure $4 \mathrm{c}$ shows the regional average precipitation amount for SEP and winter precipitation in 10-day bins. The two curves had almost opposite patterns for the cold season.

\section{b. Variation of SEP}

SEP occurred every year in the Shandong Peninsula (Fig. 5) and exhibited significant interannual variability, ranging from 6.7 to $62.3 \mathrm{~mm}$ with an annual mean of $24.1 \mathrm{~mm}$. The years 1985 and 2005 had the highest and second-highest annual amounts of SEP in the period 1962-2012. The contribution of SEP to the total precipitation of the cold season ranged from $4.8 \%$ (1992) to $82.4 \%$ (1999), once again indicating that it had a relatively large interannual variability, in particular in the 1990s. No determination could be made concerning the long-term SEP trends in these analyses because the weak upward trends as seen in Fig. 5 were not statistically significant.

Figure 6 shows the regional average change of different types of annual cold-season SEP. Annual mean
SEP was $24.1 \mathrm{~mm}$, with $16.4 \mathrm{~mm}$ or $68 \%$ occurring as snowfall. The different types of SEP showed the same characteristics of interannual variability. Snowfall accounted for $21.1 \%-100 \%$ of the total SEP. Annual mean rainfall of SEP was $4 \mathrm{~mm}$, and the pattern of interannual variability was similar to that of SEP but with an evidently smaller magnitude, accounting for $0 \%-$ $49.6 \%$ of the total SEP $\left(17.1 \% \mathrm{yr}^{-1}\right)$. Annual mean seaeffect snow-rain was $3.7 \mathrm{~mm}$, accounting for $0 \%-67.8 \%$, but it was not necessarily observed every year.

No significant long-term trend of the cold-season precipitation was detectable in these analyses, despite the fact that the total SEP amount for all categories and the snowfall exhibited a general upward trend over the study period, especially after the late 1980s.

\section{c. Relationship between surface-850-hPa temperature difference and SEP}

Sea surface-atmospheric temperature difference is an essential condition for the formation and development of SEP. Here the temperature difference between sea surface and the $850-\mathrm{hPa}$ atmospheric layer, or the surface-850-hPa temperature difference, was applied as an indicator of the possible SEPinducing factors.

Figure 7 shows that the amount and frequency of snow increased with the increase of the surface- $850-\mathrm{hPa}$ temperature difference. The snowfall is the equivalent precipitation amount of the station that had the largest precipitation within a SEP day. The $15^{\circ} \mathrm{C}$ temperature difference was an important criterion for intense snow development. Intense snow days were seen only when the temperature differences exceeded $15^{\circ} \mathrm{C}$. The weaker SEP rainfall generally occurred at a temperature 

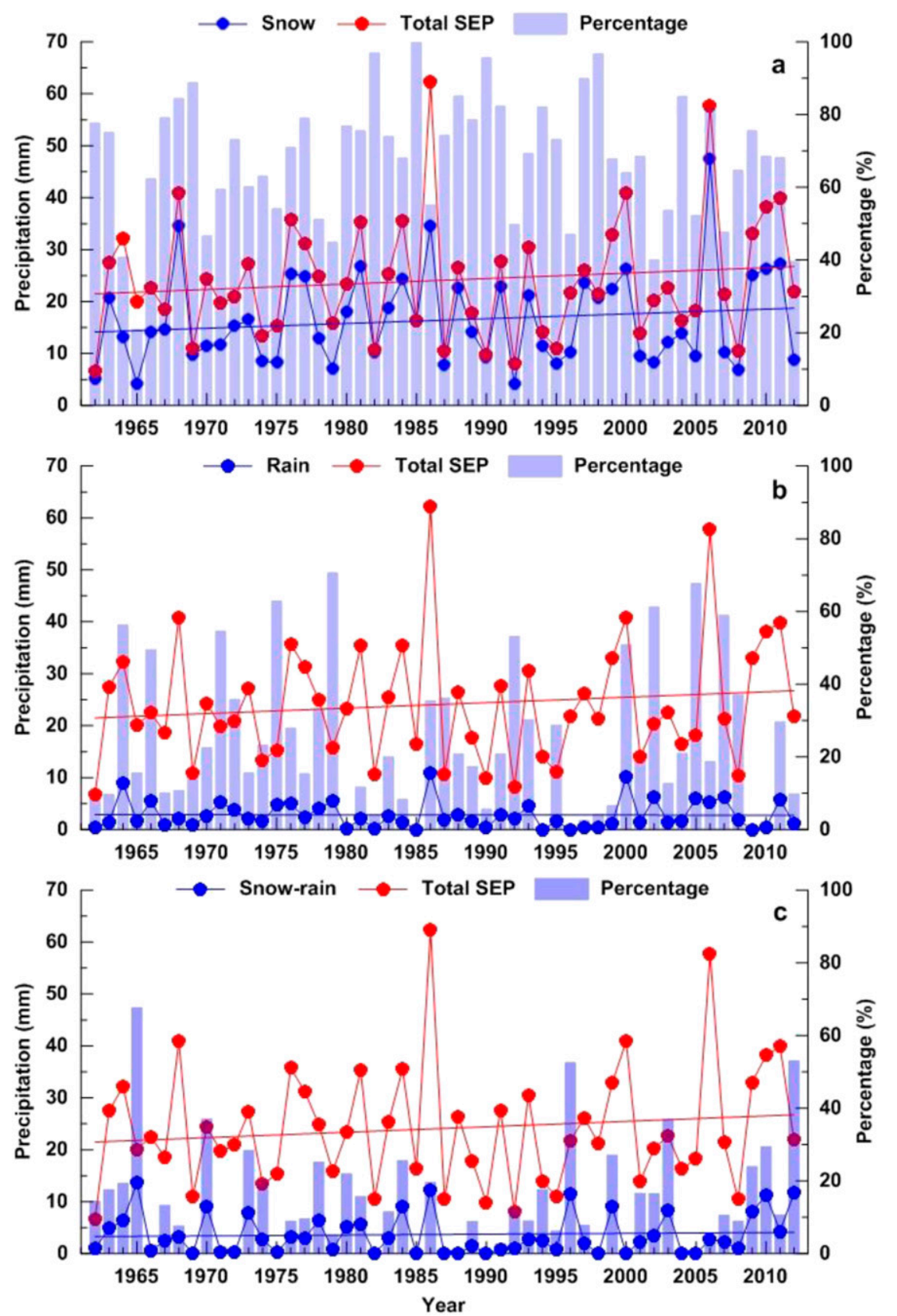

FIG. 6. Regional-averaged annual total SEP [red; identical in (a)-(c)], different types of SEP (blue), and the percentage contribution to total SEP (bars) during 1962-2012: (a) snow, (b) rain, and (c) snow-rain.

difference of $10^{\circ}-20^{\circ} \mathrm{C}$. Snow-rain days occurred between $10^{\circ}$ and $25^{\circ} \mathrm{C}$, with a similar distribution as snowfall. It was therefore obvious that SEP snow and snow-rain were most likely to occur with a surface850-hPa temperature difference of $15^{\circ}-20^{\circ} \mathrm{C}$ (see Table 4).

The positive correlation between snowfall/snowrainfall and the surface- $850-\mathrm{hPa}$ temperature difference can be explained well. The larger temperature difference meant an increase of temperature lapse rate over the Bohai Sea and the northern coastal zone of the Shandong Peninsula, leading to stronger convection and instability. These would in turn promote generation and development of SEP weather on the peninsula. A previous analysis showed that approximately $80 \%$ of surface-850-hPa temperature differences for the Lake Champlain events were greater than $13^{\circ} \mathrm{C}$, with a mean 

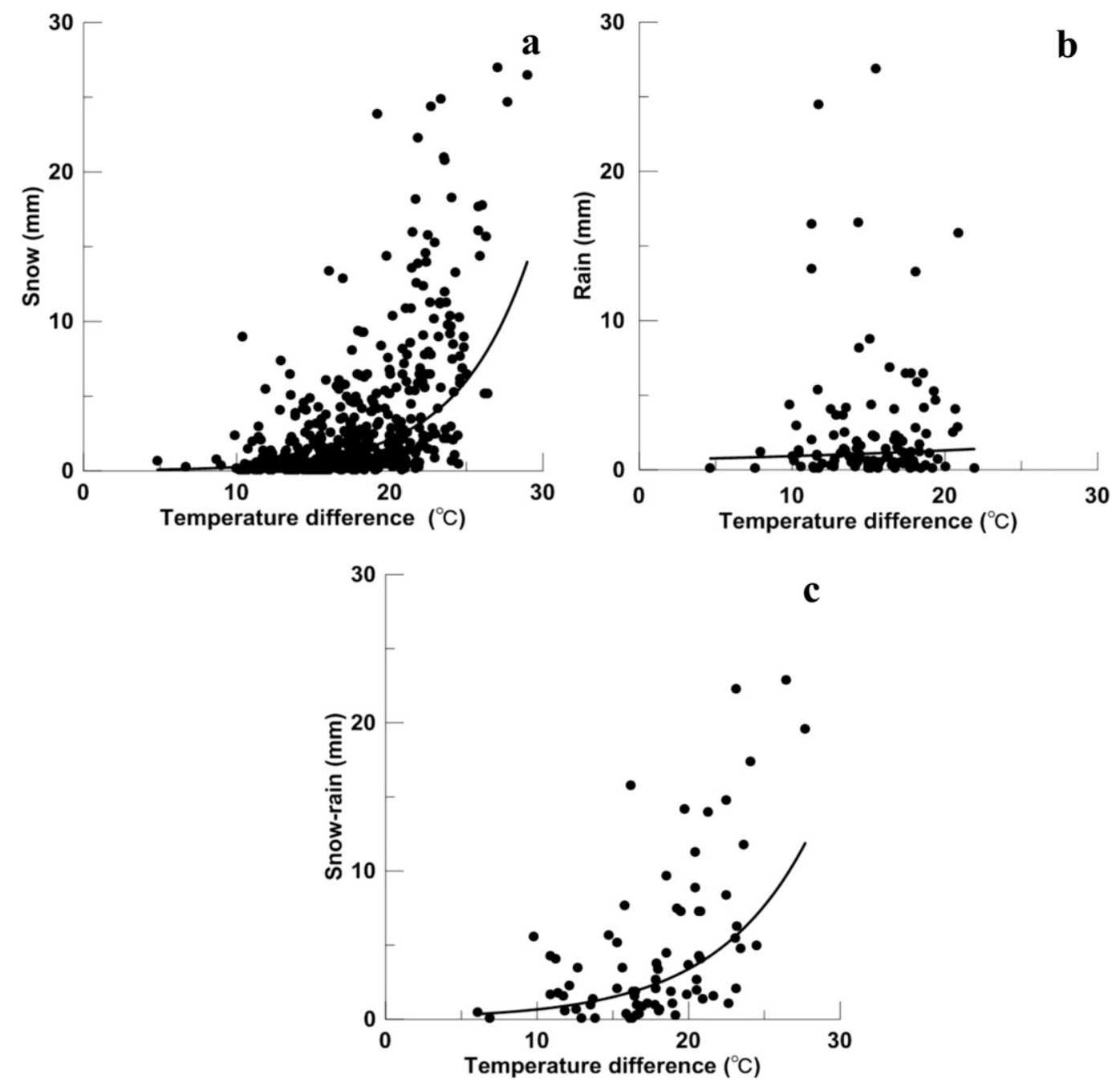

FIG. 7. Relationship between daily mean sea-850-hPa temperature difference and the maximum single-site daily SEP amount of different types and grades at stations for SEP days, 1981-2012: (a) snow (499 days), (b) rain (110 days), and (c) snow-rain (74 days).

value of $18.2^{\circ} \mathrm{C}$ (Laird et al. 2009a). In the Shandong Peninsula, mean surface-850-hPa temperature difference was $17.8^{\circ} \mathrm{C}$ for SEP snow days, $15.2^{\circ} \mathrm{C}$ for SEP rain days, and $17.5^{\circ} \mathrm{C}$ for SEP snow-rain days, with a mean of $16.8^{\circ} \mathrm{C}$ for all SEP days. Temperature differences of larger than $13^{\circ} \mathrm{C}$ accounted for $89 \%$ of the SEP snow days, $74 \%$ of SEP rain days, and $80 \%$ of SEP snow-rain days, with a mean of $86 \%$ for all SEP days. Therefore, a temperature difference of $15^{\circ} \mathrm{C}$ seems to be a critical criterion for intense snow development, which was similar to that reported for Great Salt Lake snowstorm events (Steenburgh et al. 2000).

Figure 8 shows that the frequency of snowfall days and the surface-850-hPa temperature difference had a good correspondence; both showed two maximum values during the cold season: one in late December and the other in late January. In late autumn and early winter, owing to the rapid decrease of the air temperature, the frequency of snowfall days exhibited a significant increase and reached the first maximum in late December, whereas at the same time a significant decrease could be seen in the frequency of rainfall and snow-rainfall days. Following the sharp increase of air temperature and slight decrease of SST, and a rapid decline of the surface-850-hPa temperature difference, the number of snow days decreased dramatically in February. The SST in the Bohai Sea displayed a continuous decreasing trend throughout the cold season, whereas air temperature first decreased until late January and then began to increase. This in turn caused the decrease in the frequency of snowfall. 
TABLE 4. Significance test for the exponential fits in Fig. 7. Here, $R^{2}$ is the correlation coefficient squared and $F$ is the $F$ statistic.

\begin{tabular}{lcccc}
\hline \hline & Sample size & $R^{2}$ & $F$ & Significance level \\
\hline Snow & 499 & 0.318 & 231.74 & $99 \%$ \\
Rain & 110 & 0.006 & 0.65 & Not significant \\
Snow-rain & 74 & 0.274 & 27.17 & $99 \%$ \\
\hline
\end{tabular}

In addition, as Table 5 shows, sea ice extent exhibited a significant negative correlation with snowfall and snow-rainfall of SEP in the Shandong Peninsula, indicating that snowfall and snow-rainfall would generally decrease when the sea ice area in the Bohai Sea expanded and increase when it shrank. The correlation would be stronger and more significant if light snowfall and snow-rainfall events were neglected. This is understandable because, in the case of lack of sea ice, the surface- $850-\mathrm{hPa}$ temperature difference would be larger (Table 5), facilitating the formation and development of SEP on the peninsula.

\section{d. Atmospheric conditions for SEP}

Figure 9 gives 500-hPa mean and anomalous geopotential heights for the extremely intense SEP days selected. The main pattern for geopotential height at $500 \mathrm{hPa}$ was a deep trough in the mid-high-latitude area of $110^{\circ}-140^{\circ} \mathrm{E}$ for all of the extremely intense SEP snow and snow-rain days (Figs. 9a,e and 10e). The extremely intense SEP snow and snow-rain days shared a more similar pattern for the $500-\mathrm{hPa}$ pressure level, characterized by an anomalously negative geopotential height or lower-than-normal pressure over the Shandong Peninsula and the Bohai Sea as shown by the closed center of low values. The East Asian trough (EAT) was stronger, the Shandong Peninsula was located just to the southwest of the low-value center, and the pressure gradient over this area was very large (Figs. 9a,e), allowing for strong northwesterly flow to enter the study area. In addition, the trough developed strongly on the extremely intense SEP days as compared with the day before and weakened considerably on the day after (Fig. 10). For rain days (Fig. 9c), however, the geopotential height pattern at $500 \mathrm{hPa}$ was very different, the isolines were more flat in the mid-high-latitude area, and a weaker EAT moved far northeast of the study area. For the peninsula area, only a small height gradient was seen, indicating a comparatively weaker northerly airflow.

The anomalous height fields were also similar for snow and snow-rain days (Figs. 9b,f). The 500-hPa pressure had a sharp drop over the study area, with a $>200-\mathrm{m}$ decrease in the center, indicating the deepening of the EAT. For SEP rain days (Fig. 9d), the largest decreasing

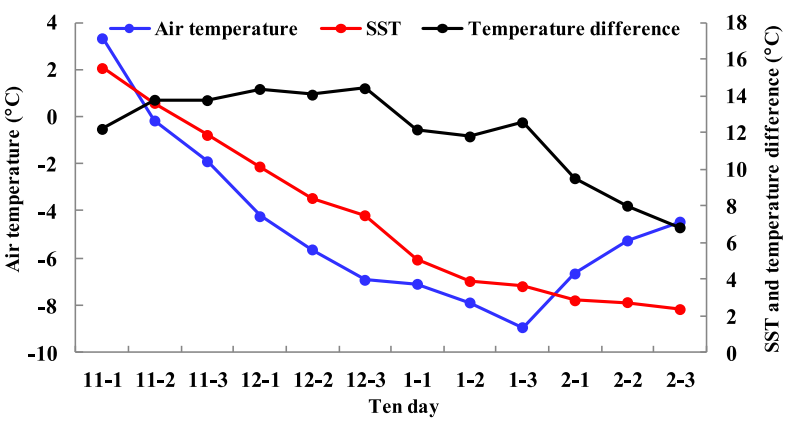

FIG. 8. Long-term mean SST, air temperature, and temperature difference in 10-day bins.

center of the geopotential height $(>90 \mathrm{~m})$ was located in the area of $70^{\circ}-80^{\circ} \mathrm{E}$, and a decrease of only approximately $30 \mathrm{~m}$ was seen over the study area. There was a large move of the negative anomalous geopotential height center at $500 \mathrm{hPa}$ (Fig. 10) from the day before the SEP days to the day after, with the largest negative value being centered over the Shandong Peninsula and the Bohai Sea on the day before and moving eastward on the following days.

Figure 11 shows the 850 -hPa mean wind field, temperature, and geopotential height of the extremely intense SEP days. Similar to the $500-\mathrm{hPa}$ field, the $850-\mathrm{hPa}$ geopotential height also exhibited a deep EAT over the study area during the extremely intense SEP snow days, with strong northwesterly wind affecting the peninsula. A low temperature center was also located to the north of the peninsula, and a sharp gradient in air temperature appeared over the peninsula. The steep gradients of temperature and geopotential height isolines were almost orthogonally distributed over the Shandong Peninsula, providing sufficient cold-air flow to the area. For the extremely intense SEP snow-rain days, the cold center $\left(-20^{\circ} \mathrm{C}\right)$ was located at a higher latitude relative to the pattern for snow days and the gradient of isolines was weaker. For the extremely intense SEP rain days, temperature isolines were distributed more zonally, indicating a weaker gradient and less cold-flow supply.

Large negative temperature anomalies were seen in the whole layer below $400 \mathrm{hPa}$ at $30^{\circ}-40^{\circ} \mathrm{N}$ for the

TABLE 5. Correlation coefficient of sea ice area of the Bohai Sea with SEP over the Shandong Peninsula.

\begin{tabular}{lccc}
\hline \hline & Snow & Rain & Snow-rain \\
\hline Sample size & 241 & 68 & 43 \\
Correlation coef & -0.238 & -0.093 & -0.339 \\
Significance level & $99 \%$ & Insignificant & $95 \%$ \\
\hline
\end{tabular}



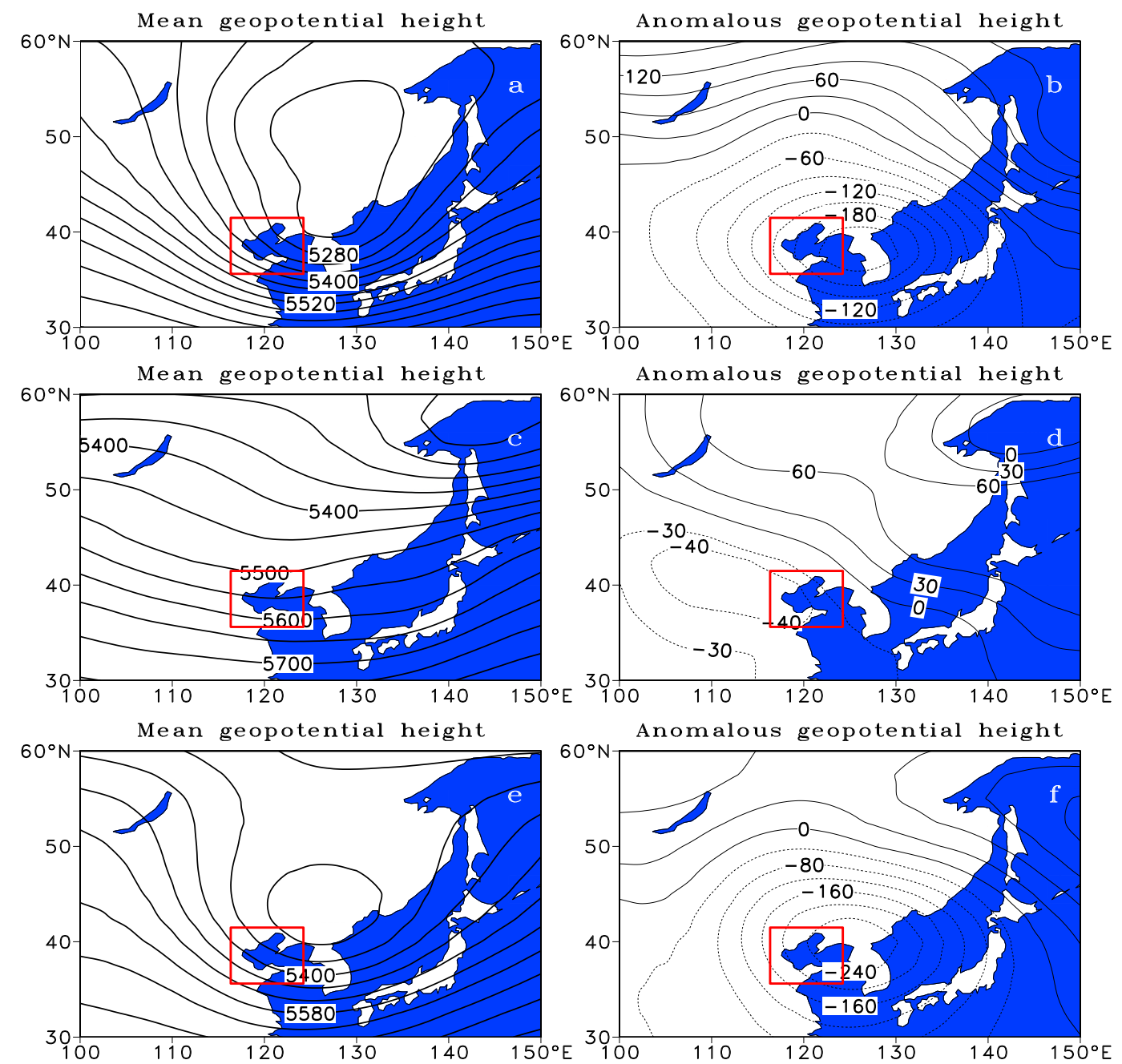

FIG. 9. The 500-hPa (left) mean and (right) anomalous geopotential height for the extremely intense SEP (a),(b) snow, (c),(d) rain, and (e),(f) snow-rain days. The study region is indicated by the red rectangle.

extreme snow (Fig. 12a) and snow-rain (Fig. 12b) cases, with an approximately $10^{\circ} \mathrm{C}$ decrease occurring over the study area. Conversely, temperature increases were seen above the 400-hPa layer, indicating that the coldair transport was constrained to low levels. For the extremely intense SEP snow-rain days, the mean temperature had a pattern that was similar to that for the extremely intense SEP snow days, with a slight difference at low levels, where the air temperature was a bit higher on snow-rain days (Fig. 12). For the extremely intense SEP rain days, the temperature below $850 \mathrm{hPa}$ was always above $0^{\circ} \mathrm{C}$. It is obvious, therefore, that the temperature anomaly at different levels corresponded well to the precipitation types of the extremely intense SEP events in the Shandong Peninsula.
The surface air temperature plays an important role in the formation and development of the SEP events. Table 6 shows the relationship between surface air temperature and different SEP types in the study area. For $89 \%$ of SEP days, the average daily mean temperature was below freezing, and the percentage of SEP days with daily mean temperature below $0^{\circ} \mathrm{C}$ generally decreased with decreasing SEP intensity. In contrast, about $94 \%$ of SEP rain days registered a daily mean temperature above freezing level. This result coincided well with the analyses by Miner and Fritsch (1997) and Laird et al. (2009a). In addition, most of the SEP snowrain days also saw a daily mean temperature above $0^{\circ} \mathrm{C}$.

Relative humidity showed a unique pattern during the extremely intense SEP events (Fig. 13). High relative humidity appeared over the study area in the lower 

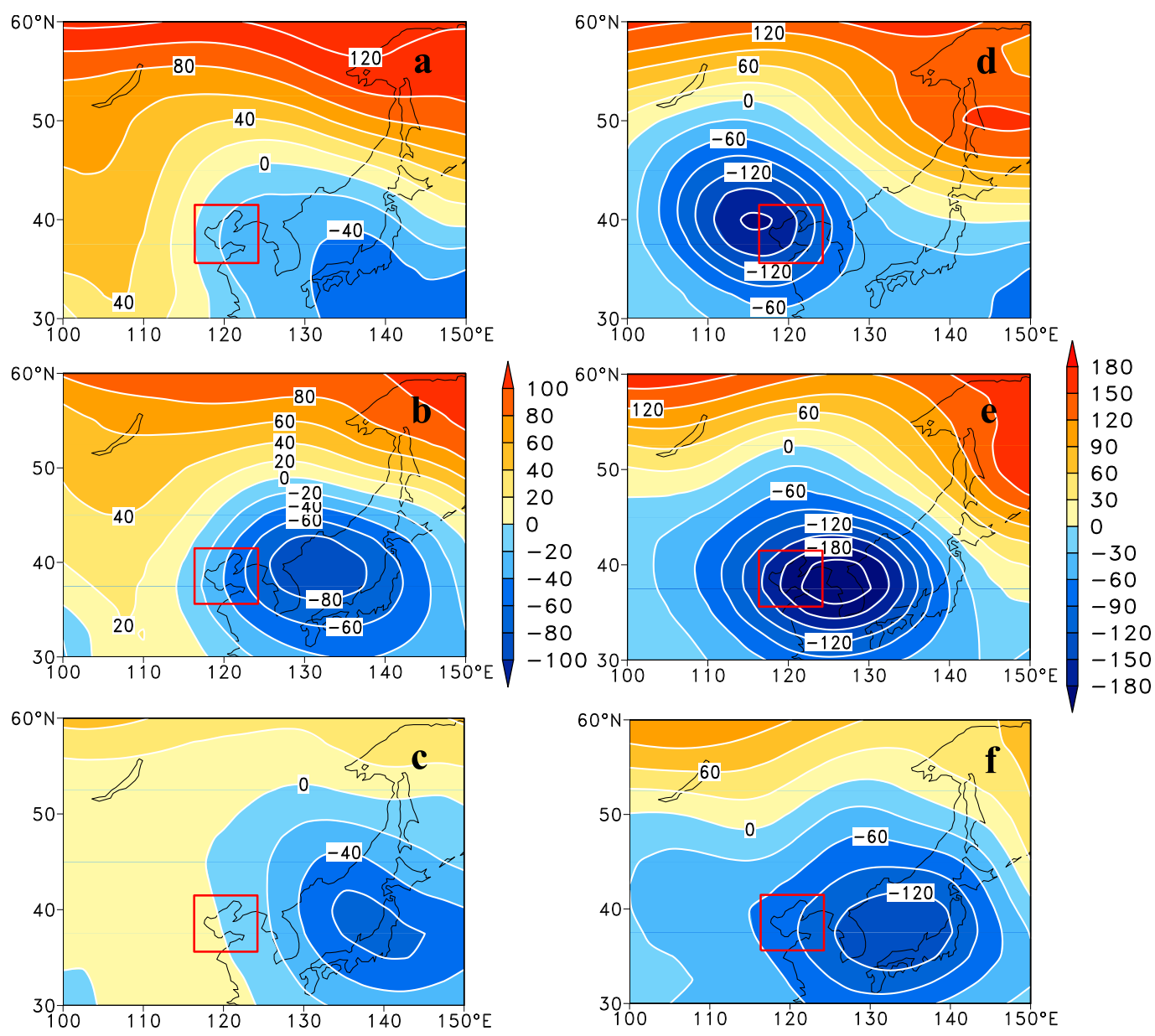

FIG. 10. Change in anomalous (left) 850- and (right) 500-hPa geopotential height of SEP snow days from -1 to +1 day [(a),(d) day before SEP snow day, (b),(e) SEP snow day, and (c),(f) day after SEP snow day]. The study region is indicated by the red rectangle.

troposphere with a value of more than $70 \%$ below the $850-\mathrm{hPa}$ level for the area of $120^{\circ}-125^{\circ} \mathrm{E}$. SEP snow days showed the highest relative humidity, followed by the SEP snow-rain days, and the SEP rain days had the lowest relative humidity in the lower layers. In all, a high relative humidity center was generally distributed around the peninsula area and relative humidity over $70 \%$ was mostly seen at low levels during the SEP processes, indicating that the convective precipitation phenomenon occurred in a thin layer of the lower troposphere during the SEP events.

\section{Discussion}

In this research, a comprehensive method is developed to identify days with SEP and to examine the spatial and temporal patterns of the SEP events and their possible linkage with the atmospheric circulation anomaly.
It is obvious that the annual regional average SEP precipitation in the study area ranges generally from 10 to $50 \mathrm{~mm}$ (Fig. 5). The amount is small relative to those in other regions of the world. An intense snowfall event over the Shandong Peninsula is therefore largely dwarfed in comparison with that of the Great Lakes, and it would be called a moderate or even light event outside the study area. A Lake Ontario winter storm regularly produces lake-effect precipitation of more than $60 \mathrm{~mm}$ in merely $24 \mathrm{~h}$ (Campbell et al. 2016). The Shandong Peninsula, like most areas of northern China, has a climate that differs somewhat from those in other regions of the world. The climate on the peninsula is characterized by a very dry winter because of the strong prevailing winter monsoon flow from the inland Asian continent. Precipitation is extremely low in winter, that is, usually less than $60 \mathrm{~mm}$ from December to February, accounting for less than $10 \%$ of the annual total amount. 


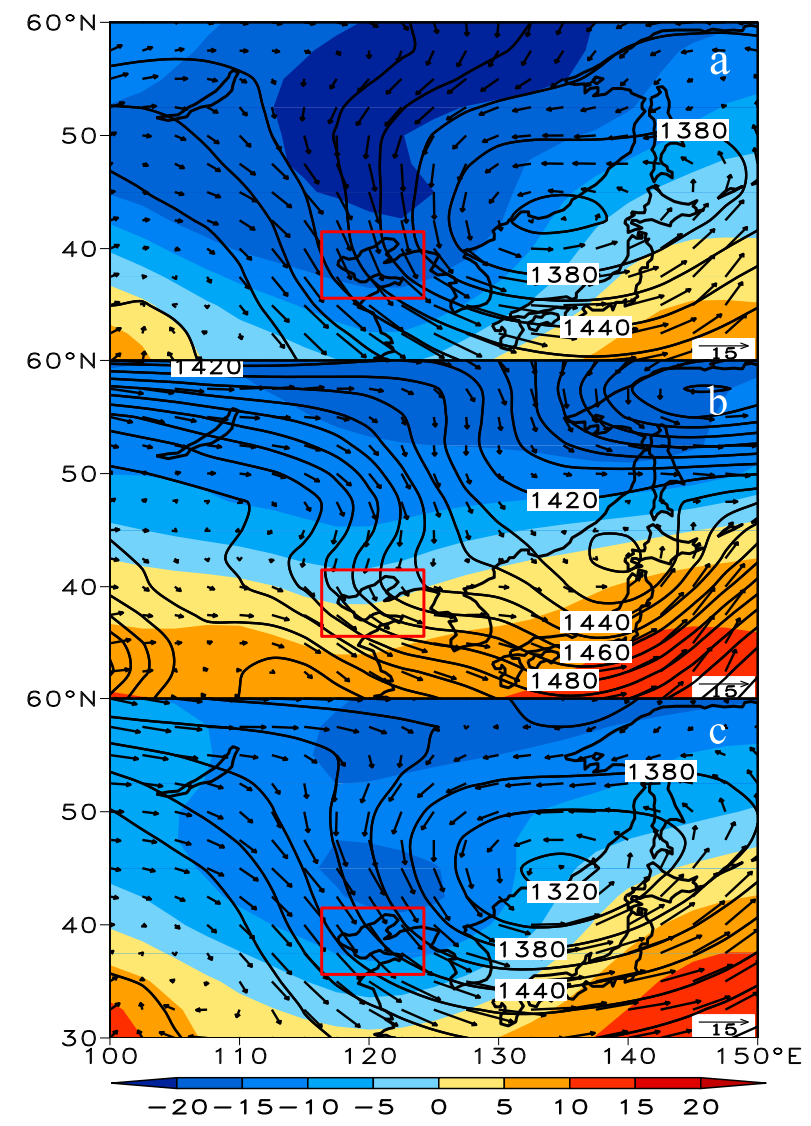

FIG. 11. The 850-hPa mean geopotential height (solid lines every $30 \mathrm{hPa}$ ), temperature (shaded scale, at $5^{\circ} \mathrm{C}$ intervals), and wind field (vectors) for extremely intense SEP (a) snow, (b) rain, and (c) snow-rain days. The study region is indicated by the red rectangle.

This is the main reason why the sea-effect events in the area produce such low accumulated precipitation in comparison with that of the other regions.

With regard to the temporal and spatial variation of the SEP snowfall, our results are generally consistent with the main characteristics as found in the previous studies (e.g., S. Zhou et al. 2011; Yu et al. 2011). The earlier studies have been focused on sea-effect snowfall, however, and none examined the SEP rainfall and snow-rainfall. We classify and analyze the three categories of the SEP events in the Shandong Peninsula. Our analysis indicates the importance of the SEP rain and snow-rain events in addition to the SEP snow days. Rain and snow-rain days account for $26.1 \%$ of the total number of SEP days, with some of the rain and snowrain events even bringing heavy precipitation. Their incorporation in this study is a significant improvement over the previous studies.

It is also obvious that the previous works were mostly focused on the SEP characteristics merely as a weather phenomenon and its synoptic origin, and the climatological characteristics and long-term variation of different types and grades of SEP events have been overlooked to a large extent. In this work, we make a more thorough analysis of the climatological characteristics and long-term variation of the different categories and grades of SEP events over the past more than one-half of a century. The main atmospheric circulation factors for, and the indicators of, the formation and development of extremely intense SEP events are also analyzed in this paper. Although further work is needed to understand better the full spectrum of influential factors and the dynamic mechanism, the findings from this analysis-including that SEP snowfall and snowrainfall have a significant positive correlation with the surface-850-hPa temperature difference and a negative correlation with the sea ice extent of the Bohai Sea, as well as that there is a close linkage of the extremely intense SEP events with key East Asian atmospheric circulation indices, air temperature, and humidity fieldswill be helpful in understanding this unique weather and climatic phenomenon, and also in forecasting and prediction of intense SEP events in the study area and beyond. It is noteworthy that the SEP events in the Shandong Peninsula, especially the intense snowfall of the SEP, increase to a certain extent over the time period analyzed, especially after the late 1980s, despite the fact that the upward trend was not statistically significant. This might be related to the overall warming of the Bohai Sea and the decline of sea ice extent after the midto late 1980s, which might be caused by large-scale climate change and variability (Zhou and Ren 2011; Ren et al. 2012). The projected climate warming and the multidecadal temperature variation of East Asia in the coming decades would likely change the sea ice extents of the Bohai Sea and would therefore affect the frequency and intensity of SEP events in the study area in the decades to come.

A deficiency in this investigation is that precipitation data with higher temporal resolution are unavailable for the time being, which restricts our ability to determine the duration and hourly intensity of the SEP. Furthermore, because SEP is a mesoscale process superimposed on a synoptic-scale background, the ability to differentiate the two processes remains a most challenging problem for future research of SEP and LEP. One of the remaining issues in identifying SEP events, for example, might be related to the possible effect from the sea breeze and synoptic precipitation. The sea-breeze circulation on the northern coast of the Shandong Peninsula is the weakest in wintertime, and it generally occurs in late spring and early summer. In winter, the sea-breeze circulation, if 


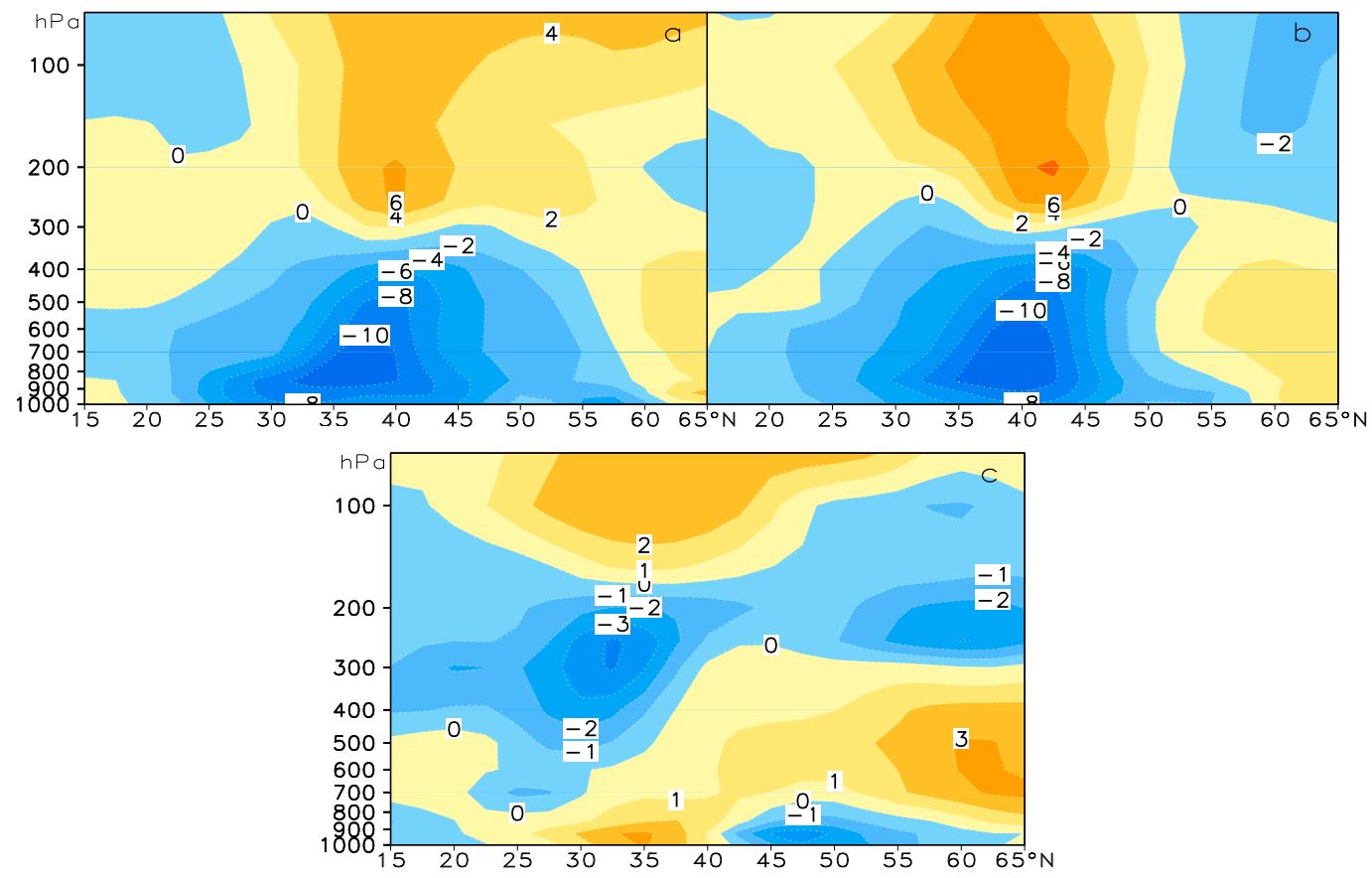

FIG. 12. Latitude-altitude profile of air temperature anomaly at $122.5^{\circ} \mathrm{E}$ (departure from $1981-2010$ mean) for the extremely intense SEP (a) snow, (b) snow-rain, and (c) rain days.

any, is submerged by strong cold-air flow, and sea ice over the Bohai Sea is another reason for the unapparent sea-breeze circulation of the northern coastal area of the peninsula (Wang and Song 1988). In the southern Bohai Sea, where there is an area of open water, the sea surface temperature is usually higher than that of the land surface in winter, and a land breeze rather than a sea breeze will develop, even in daytime. Seabreeze-initiated precipitation may therefore have less effect on identifying SEP days.

The criteria for identifying SEP events were developed with consideration of the specific climate condition of the study area, and they would be applicable to the analysis. Nevertheless, combined use of multivariable hourly records and satellite and radar data in future work would be helpful in differentiating the mesoscale SEP from the background synoptic process. In addition, it is also interesting to examine further the synchronous and lagged influence of planetary-scale atmosphere-ocean variability on the formation and development of SEP events in the Shandong Peninsula.

\section{Conclusions}

We analyzed the climatological characteristics and longterm variation of cold-season (November-February) SEP in the Shandong Peninsula using the observed daily data from 123 stations for the period 1962-2012, and also the linkage of the extremely intense SEP occurrences with a few key atmospheric circulation indices, surface-850-hPa temperature difference, sea ice area, lower-tropospheric temperature, and humidity using reanalysis data and other kinds of observations. The following conclusions were drawn:

1) A total of 1173 SEP days were identified during 1962-2012, which were further classified as snow days $(73.7 \%)$, rain days $(16.1 \%)$, and snow-rain days $(10.1 \%)$. Together, rain days and snow-rain days

TABLE 6. Number of different types of SEP precipitation days at different surface temperatures $T$.

\begin{tabular}{lcccccc}
\hline \hline & \multicolumn{3}{c}{ Snow } & & \\
& \multicolumn{1}{c}{ Intense snow } & Heavy snow & Moderate snow & Light snow & Rain & Snow-rain \\
\hline Total days & 50 & 94 & 126 & 595 & 189 \\
$T<0^{\circ} \mathrm{C}$ & $46(92 \%)$ & $87(93 \%)$ & $106(84 \%)$ & $515(87 \%)$ & $11(6 \%)$ & $31(26 \%)$ \\
$T \geq 0^{\circ} \mathrm{C}$ & 4 & 7 & 20 & 80 & 178 & 88 \\
\hline
\end{tabular}




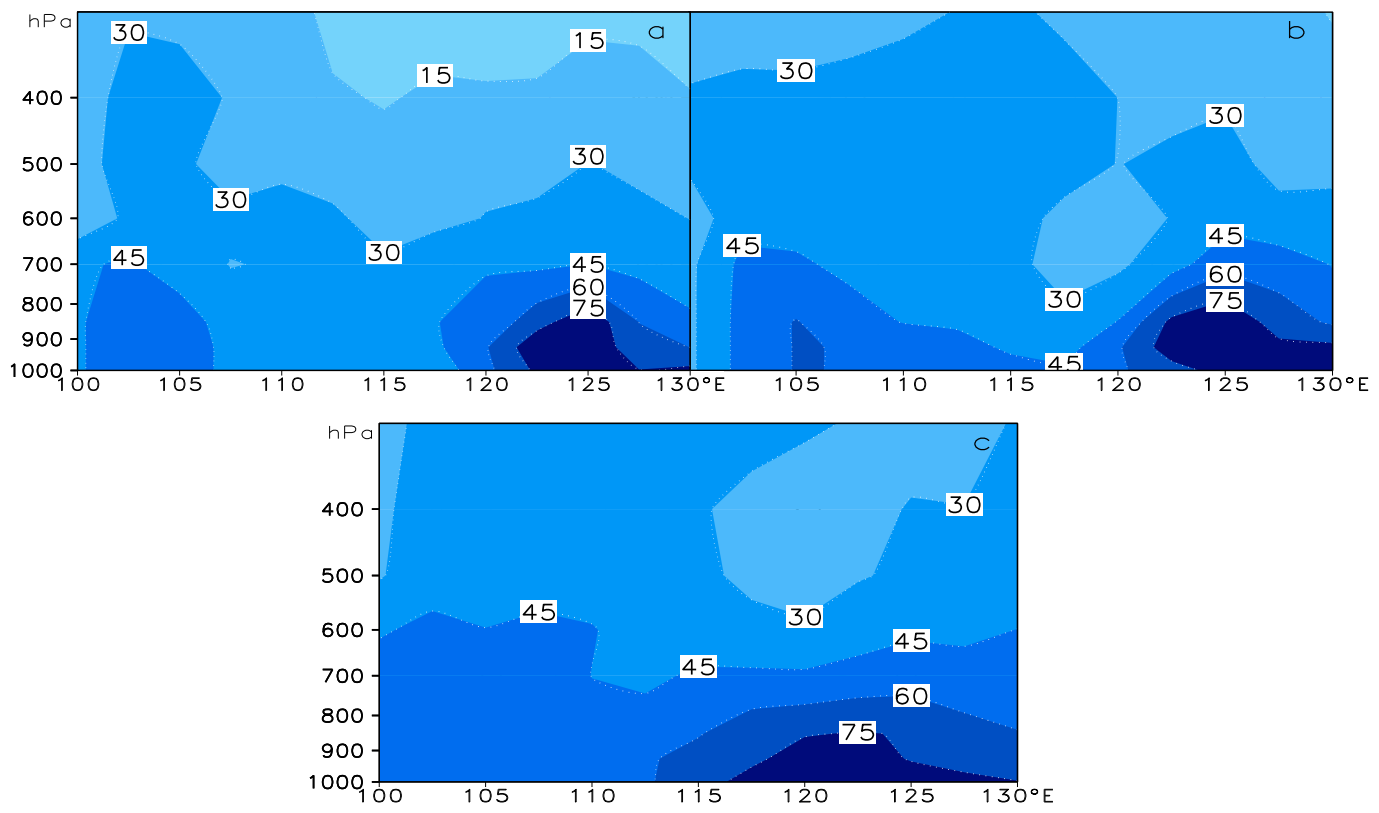

FIG. 13. Longitude-altitude profile of mean relative humidity at $37.5^{\circ} \mathrm{N}$ for the extremely intense SEP (a) snow,

(b) snow-rain, and (c) rain days.

accounted for $26.2 \%$ of SEP days, and they occasionally brought heavy precipitation.

2) December was the month with the greatest range of intensity of SEP precipitation. November was the month when SEP rain and snow-rain days occurred most frequently. SEP snowfall was primarily distributed in the northeasternmost part of the Shandong Peninsula, whereas SEP rainfall occurred along the shoreline and islands. The maximum SEP precipitation was always located near the northeastern tip of the peninsula.

3) A temperature difference of $10^{\circ} \mathrm{C}$ between the sea surface and the 850 -hPa level was required to trigger SEP, with a $10^{\circ}-15^{\circ} \mathrm{C}$ temperature difference for light snow, a $15^{\circ}-20^{\circ} \mathrm{C}$ temperature difference for moderate and heavy snow, and a temperature difference of higher than $25^{\circ} \mathrm{C}$ for intense snow.

4) A deeper East Asian trough at the $500-\mathrm{hPa}$ level developed over the southwest of the study area on the extremely intense SEP days. The $850-\mathrm{hPa}$ temperature isolines and geopotential height isolines were orthogonally distributed, indicating cold-air advection affecting the Bohai Sea and the Shandong Peninsula. Anomalously low temperature and high relative humidity also appeared in the lower troposphere during the SEP events, facilitating stronger convection in a thin layer of the lower troposphere.

Acknowledgments. This study is financed by the Ministry of Science and Technology of China (Fund
2018YFA0605603) and the China Natural Science Foundation (CNSF) (Fund 41575003).

\section{REFERENCES}

Alcott, T. I., W. J. Steenburgh, and N. F. Laird, 2012: Great Salt Lake-effect precipitation: Observed frequency, characteristics, and associated environmental factors. Wea. Forecasting, 27, 954-971, https://doi.org/10.1175/WAF-D-12-00016.1.

Braham, R. R., Jr., and M. J. Dungey, 1984: Quantitative estimates of the effect of Lake Michigan on snowfall. J. Climate Appl. Meteor., 23, 940-949, https://doi.org/10.1175/1520-0450(1984) 023<0940:QEOTEO > 2.0.CO;2.

Burnett, A. W., M. E. Kirby, H. T. Mullins, and W. P. Patterson, 2003: Increasing Great Lake-effect snowfall during the twentieth century: A regional response to global warming? J. Climate, 16, 3535-3542, https://doi.org/10.1175/1520-0442(2003)016<3535: IGLSDT>2.0.CO;2.

Campbell, L. S., W. J. Steenburgh, P. G. Veals, T. W. Letcher, and J. R. Minder, 2016: Lake-effect mode and precipitation enhancement over the Tug Hill Plateau during OWLeS IOP2b. Mon. Wea. Rev., 144, 1729-1748, https://doi.org/10.1175/MWR-D-15-0412.1.

Chu, Z., and J. H. Li, 2012: Relationship of high-altitude situation and the cold-air intense snow in the Shandong Peninsula (in Chinese with English abstract). Meteor. Environ. Sci., 35, 44-48.

Cordeira, J. M., and N. F. Laird, 2008: The influence of ice cover on two lake-effect snow events over Lake Erie. Mon. Wea. Rev., 136, 2747-2763, https://doi.org/10.1175/2007MWR2310.1.

Cui, Y., J. H. Li, F. Q. Zhang, and C. Y. Wang, 2008: Statistical analysis of cold air outbreak on Shandong Byland (in Chinese with English abstract). Meteor. Environ. Sci., 31, 22-26.

Farley Nicholls, J., and R. Toumi, 2014: On the lake effects of the Caspian Sea. Quart. J. Roy. Meteor. Soc., 140, 1399-1408, https://doi.org/10.1002/qj.2222. 
Huang, C., X. Y. Shen, J. H. Sun, and L. L. Qi, 2008: Analysis of coastal front heavy snowfall in Shandong Peninsula (in Chinese with English abstract). Climatic Environ. Res., 13, 567-583.

Ikeda, S., R. Wakabayashi, K. Izumi, and K. Kawashima, 2009: Study of snow climate in the Japanese Alps: Comparison to snow climate in North America. Cold Reg. Sci. Technol., 59, 119-125, https://doi.org/10.1016/j.coldregions.2009.09.004.

Jiang, J., M. Wei, H. Kang, and X. D. Zhang, 2010: Mechanism and multi-scale characteristics if snowstorm process occurred in Shandong Peninsula in December 2005 (in Chinese with English abstract). Trans. Atmos. Sci., 33, 328-335.

Kalnay, E., and Coauthors, 1996: The NCEP/NCAR 40-Year Reanalysis Project. Bull. Amer. Meteor. Soc., 77, 437-471, https:// doi.org/10.1175/1520-0477(1996)077<0437:TNYRP>2.0.CO;2.

Kindap, T., 2010: A severe sea-effect snow episode over the city of Istanbul. Nat. Hazards, 54, 707-723, https://doi.org/10.1007/ s11069-009-9496-7.

Laird, N. F., J. Desrochers, and M. Payer, 2009a: Climatology of lakeeffect precipitation events over Lake Champlain. J. Appl. Meteor. Climatol., 48, 232-250, https://doi.org/10.1175/2008JAMC1923.1.

_ R. Sobash, and N. Hodas, 2009b: The frequency and characteristics of lake-effect precipitation events associated with the New York State Finger Lakes. J. Appl. Meteor. Climatol., 48, 873-886, https://doi.org/10.1175/2008JAMC2054.1.

,-- , and -2010 : Climatological conditions of lake-effect precipitation events associated with the New York State Finger Lakes. J. Appl. Meteor. Climatol., 49, 1052-1062, https://doi.org/10.1175/2010JAMC2312.1.

—, S. A. Ganetis, A. Stieneke, and S. A. Tushaus, 2016: Climatology of lake-effect precipitation events over Lake Tahoe and Pyramid Lake. J. Appl. Meteor. Climatol., 55, 297-312, https:// doi.org/10.1175/JAMC-D-14-0230.1.

Li, B., J. Li, Q. H. Wang, and K. Yang, 2011: Diagnosis analysis of one cold airflow snowfall in Shandong Peninsula. Meteor. Environ. Res., 2, 34-36.

Li, P., G. Fu, J. T. Guo, and N. Liu, 2009: An analysis and numerical modeling of a snowstorm event over Shandong Peninsula in December, 2005 (in Chinese with English abstract). Period. Ocean Univ. China, 39, 173-180.

Miner, T. J., and J. M. Fritsch, 1997: Lake-effect rain events. Mon. Wea. Rev., 125, 3231-3248, https://doi.org/10.1175/1520-0493(1997) $125<3231$ :LERE $>2.0$. CO 2 .

Nam, H., B. G. Kim, S. O. Han, C. Lee, and S. S. Lee, 2014: Characteristics of easterly-induced snowfall in Yeongdong and its relationship to air-sea temperature difference. AsiaPac. J. Atmos. Sci., 50, 541-552, https://doi.org/10.1007/ s13143-014-0044-3.

Passarelli, R. E., and R. R. Braham, 1981: The role of the winter land breeze in the formation of Great Lake snow storms. Bull. Amer. Meteor. Soc., 62, 482-492, https://doi.org/10.1175/ 1520-0477(1981)062<0482:TROTWL>2.0.CO;2.

Payer, M., J. Desrochers, and N. F. Laird, 2007: A lake-effect snow band over Lake Champlain. Mon. Wea. Rev., 135, 3895-3900, https://doi.org/10.1175/2007MWR2031.1.

Ren, G., Y. H. Ding, Z. C. Zhao, J. Y. Zheng, T. W. Wu, G. L. Tang, and Y. Xu, 2012: Recent progress in studies of climate change in China. Adv. Atmos. Sci., 29, 958-977, https://doi.org/ 10.1007/s00376-012-1200-2.

Shan, B., C. Zhang, J. H. Li, Y. S. Cui, and C. Zhang, 2006: Diagnostic analysis of Weihai early winter first snowstorm in 2005 (in Chinese with English abstract). J. Shandong Meteor., 26, 17-18.

Steenburgh, W. J., S. F. Halvorson, and D. J. Onton, 2000: Climatology of lake-effect snowstorms of the Great Salt
Lake. Mon. Wea. Rev., 128, 709-727, https://doi.org/10.1175/ 1520-0493(2000)128<0709:COLESO > 2.0.CO;2.

Sun, X., W. Y. Wang, L. F. Yan, Y. H. Wang, and Y. Sui, 2007: Analysis of the Shandong Peninsula particularly heavy snowstorm in 2005 (in Chinese with English abstract). Period. Ocean Univ. China, 37, 879-884.

Tan, L., 1992: Monthly anomalous precipitation analysis of Wuzhou. J. Guizhou Meteor., 16, 16-18.

Tardy, A., 2000: Lake-effect and lake-enhanced snow in the Champlain Valley of Vermont. NWS Eastern Region Tech. Attach. 2000-05, 27 pp., https://www.weather.gov/media/erh/ ta2000-05.pdf.

Veals, P. G., and W. J. Steenburgh, 2015: Climatological characteristics and orographic enhancement of lake-effect precipitation east of Lake Ontario and over the Tug Hill Plateau. Mon. Wea. Rev., 143, 3591-3609, https://doi.org/10.1175/ MWR-D-15-0009.1.

Wang, C., and X. L. Song, 1988: Sea land breezes of the northern coast of Shandong Peninsula (in Chinese). Acta Oceanol. Sin., 10, 678-686.

Yang, C., Z. C. Li, B. Zhou, Y. K. Chen, and J. J. Zhu, 2007a: Mesoscale analysis of ocean-effect snowstorms in the south coastland of Bohai Sea (in Chinese with English abstract). J. Nanjing Inst. Meteor., 30, 857-865.

$\longrightarrow$ X. S. Zhou, and Y. H. Wang, 2007b: Climatic features and previous signal of cold airflow snowfall in Shandong Peninsula (in Chinese with English abstract). Meteor. Mon., 33, 76-82.

- Z. Y. Tao, and Z. C. Li, 2009: Overview of research on ocean (lake)-effect snow (in Chinese with English abstract). Mar. Sci. Bull., 28, 81-88.

Yu, Q., F. X. Zhou, and Q. Wang, 2009: Sea effects on local snows at Shandong Peninsula (in Chinese with English abstract). Huadong Shifan Daxue Xuebao, 3, 160-169.

,-- , Z. D. Tang, Q. Wang, and Y. Liu, 2011: Formation of the local precipitation climate in Shandong Peninsula in winter (in Chinese with English abstract). Plateau Meteor., 30, 719-726.

Zhang, Y., S. W. Shou, Y. Q. Wang, J. Zhou, and H. C. Lu, 2008: Mesoscale characteristics analysis on a snow storm in Shandong Peninsula (in Chinese with English abstract). J. Nanjing Inst. Meteor., 31, 51-60.

Zheng, L., S. Y. Shi, and S. M. Hou, 2003: Contribution of the Bohai Sea's special topography to cold vortex snow event (in Chinese with English abstract). Meteorology, 29, 49-52.

Zhou, S., M. H. Cong, Z. M. Wu, S. L. Yan, C. F. Yang, and J. J. $\mathrm{Zhu}$, 2008: Characteristics and maintaining mechanisms of sustained cold-air outbreak snowstorms processes in Shandong Peninsula during December 3-21, 2005 (in Chinese with English abstract). J. Appl. Meteor. Sci., 19, 444-453.

- H. J. Li, Z. M. Wu, and Q. F. Lin, 2011: Climatic characteristics and causality of cold air-outbreak snowstorm events in Shandong Peninsula in winter (in Chinese with English abstract). Ziran Zaihai Xuebao, 20, 91-98.

Zhou, X., C. F. Yang, and S. L. Zhang, 2011: Study on possible mechanism of terrain influence to cold airflow snowstorm (in Chinese with English abstract). J. Anhui Agric. Sci., 39, 19419-19422.

Zhou, Y., and G. Y. Ren, 2011: Change in extreme temperature events frequency over mainland China during 1961-2008. Climate Res., 50, 125-139, https://doi.org/10.3354/cr01053.

Zhu, Y., Z. M. Wu, Q. F. Lin, and S. L. Zhou, 2010: Analysis of a cold-air outbreak snowstorm event affected by Taihang Mount in Shandong Peninsula (in Chinese with English abstract). Period. Ocean Univ. China, 40, 1-8. 